\title{
Pengaruh penyuluhan dengan media poster terhadap peningkatan pengetahuan dan penerapan teknik pengolahan bahan makanan pada penjamah makanan di Panti Asuhan Kota Banda Aceh \\ The effect of counseling with poster media on increasing knowledge and application of food processing techniques at food handlers at Orphanage, Banda Aceh
}

SAGO: Gizi dan Kesehatan 2020, Vol. 1(2) 195-200 (C) The Author(s) 2020

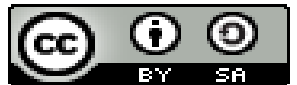

DOI: http://dx.doi.org/10.30867/sago.v1i2.415 https://ejournal.poltekkesaceh.ac.id/index.php/

Poltekkes Kemenkes Aceh

Nanda Nabila ${ }^{1 *}$, Andriani $\mathrm{Ms}^{2}$

\begin{abstract}
Background: Food processing workers for orphanage play an important role in processing large quantities of food. The problems that exist in the food handler staff at orphanages lack knowledge about good food processing techniques.

Objectives: To find out whether there is an influence of counseling with poster media on increasing the knowledge and implementation of food processing techniques in food handlers in the orphanage of Banda Aceh.

Methods: This study is descriptive analytical with an observation approach, Quasi Experiment design, with pre and post design without control. The sample is 24 food handlers. This research was conducted in June 2019. Data analysis used the Dependent T-test at a confidence level of $95 \%$.

Results: Results There was an increase in knowledge in food handlers by 9.50 , namely before counseling 22.25 , while after counseling the average knowledge in food handlers increased to 31.75. The increase in the application of food handlers was 8.50, which was before counseling 15.75, whereas after extension the average application for food handlers increased to 24.25. The results of the knowledge category T-test test obtained $p=0.001(p<0.05)$, the application category obtained $p=0.006(p<0.05)$.

Conclusion: There is a significant effect of counseling with poster media on increasing knowledge and application of food handlers in processing food ingredients at Nirmala Orphanage.
\end{abstract}

\section{Keywords}

Counseling, food processing techniques, knowledge, posters

\begin{abstract}
Abstrak
Latar Belakang: Tenaga pengolahan makanan bagi penghuni panti asuhan memegang peranan penting dalam pengolahan makanan dengan jumlah besar. Permasalahan yang ada pada tenaga penjamah makanan dipanti asuhan kurang memiliki pengetahuan tentang teknik pengolahan bahan makanan yang baik

Tujuan: untuk mengetahui apakah ada pengaruh penyuluhan dengan media poster terhadap peningkatan pengetahuan dan penerpan teknik pengolahan bahan makanan pada penjamah makanan pada panti asuhan di Kota Banda Aceh Metode: Penelitian ini bersifat deskriptif analitik dengan pendekatan observasi, desain Quasi Eksperimen, dengan rancangan pre dan post tanpa control. Jumlah sampel 24 orang penjamah makanan. Penelitian ini dilakukan pada bulan Juni 2019. Analisis data menggunakan uji Dependen T-test pada tingkat kepercayaan 95\%.
\end{abstract}

1 Proram Studi D-IV Gizi, Jurusan Gizi Politeknik Kesehatan Kemenkes Aceh, Aceh, Indonesia. E-mail: nabilananda1998@gmail.com

2 Jurusan Gizi Politeknik Kesehatan Kemenkes Aceh, Aceh, Indonesia. E-mail: aan fifa@yahoo.com 
Hasil: Hasil penelitian ini adanya peningkatan pengetahuan pada penjamah makanan sebesar 9.50 yaitu sebelum penyuluhan 22.25 , sedangkan setelah penyuluhan rerata pengetahuan pada penjamah makanan meningkat menjadi 31.75. Adanya peningkatan penerapan pada penjamah makanan sebesar 8.50 yaitu sebelum penyuluhan 15.75 , sedangkan setelah penyuluhan rerata penerapan pada penjamah makanan meningkat menjadi 24.25. Hasil uji T-test kategori pengetahuan diperoleh nilai $p=0.001(p<0.05)$, kategori penerapan diperoleh nilai $p=0.006(p<0.05)$.

Kesimpulan: Terdapatnya pengaruh signifikan penyuluhan dengan media poster terhadap peningkatan pengetahuan dan penerapan penjamah makanan dalam pengolahan bahan makanan di Panti Asuhan Kota Banda Aceh.

\section{Kata Kunci}

Pengetahuan, Penyuluhan, Poster, dan Teknik Pengolahan Bahan Makanan

\section{Pendahuluan}

$\mathrm{M}$ akanan yang dapat dikonsumsi harus melalui teknik pengolahan yang baik. Pengolahan makanan adalah suatu kegiatan atau memasak bahan makanan mentah menjadi makanan yang siap dimakan, berkualitas dan aman untuk dikonsumsi ${ }^{[1]}$. Proses pemasakan pada institusi berbeda dengan pemasakan jumlah porsi sedikit. Pada system penyelenggaraan makanan institusi, dimana bahan yang sudah dipersiapkan dalam porsi banyak. Oleh karena itu, agar tercipta rasa hidangan dapat dipertahankan kualitasnya, maka diperlukan tahaptahap yang berbeda bila pemasakan dalah jumlah sedikit (Wardhani, 2014).

Mekanisme teknik pengolahan makanan yaitu mulai dari persiapan, pengolahan dan penyajian. Persiapan memasak terdiri dari dua hal yaitu persiapan bahan yang akan dimasak dan persiapan alat memasak (Syahrizal, 2017). Persiapan bahan meliputi penimbangan (weighing), pencucian (washing), penyiangan (triming), pemotongan (cut process), memeras (squeeze), menyaring (shift), mengocok (whisk), mencampur (toss), pencecaman (marinate), pengisian (stuffing), adonan penggoreng (frying butter), menggiling (grind), barde \& larde, pembumbuan (seasoning), panir, dan adonan butter-flour (roux). Persiapan alat memasak terdiri dari tungku memasak, hot plate, oven, fryer, boiler, salamander dan steamer (Putri et al., 2017).

Pengolahan merupakan metode memasak yang terdiri dari metode memasak basah dan metode memasak kering. Metode memasak basah terdiri dari merebus (boiling), simmering, poaching, stewing, braising, steaming, blancing. Metode memasak kering terdiri dari grilling, baking, roasting, deep frying, dan shallow frying (Atmoko, 2017).

Selama tahun 2011 Badan POM telah mencatat 128 kejadian/kasus keracunan pangan di 25 propinsi di Indonesia. Sebanyak 18.144 orang terpapar, sedangkan kasus KLB keracunan pangan yang dilaporkan sebanyak 6.901 orang sakit dan 11 orang meninggal dunia
(BPOM, 2016). Oleh karena itu perlu suatu tindakan untuk mencegahnya, yaitu dengan melaksanakan tehnik pengolahan makanan yang baik pada dapur, dengan adanya pelaksanaan teknik pengolahan makanan yang baik akan menggurangi terjadinya keracunan (Rahmadhani \& Sumarmi, 2017). Maka dari itu penelitian ini tertarik untuk melakukan penelitian tentang Pengaruh Penyuluhan Dengan Media Poster Terhadap Peningkatan Pengetahuan Dan Penerapan Teknik Pengolahan Bahan Makanan Pada Penjamah Makanan di panti asuhan Nirmala.

\section{Metode}

Metode yang digunakan dalam penelitian ini bersifat deskriptif kuantitatif dengan pendekatan observasi, pendekatan penelitian ini dengan desain Quasi Eksperimen, dengan rancangan pre dan post tanpa control bertujuan menganalisis pengaruh (sebelum dan sesudah) pemberian penyuluhan (Creswell \& Poth, 2017).

Penelitian ini diawali dengan observasi terhadap responden saat sedang melakukan tehnik pengolahan makanan, setelah itu responden mengisi kuesioner (pretest) kemudian dilakukan penyuluhan, setelah dilakukan penyuluhan penyuluh menempelkan poster di bagian dapur supaya responden dapat melihat setiap saat sedang pengolahan bahan makanan. Setelah satu minggu, penyuluh kembali ke panti untuk melakukan observasi dan pemberian kuesioner (posttest). Kuesioner yang digunakan adalah kuesioner mengenai pengetahuan dan langkah-langkah teknik pengolahan bahan makanan (Abdullah, 2016).

Penelitian ini dilakukan pada tanggal 19-27 Juni 2019 pada beberapa Panti Asuhan di Kota Banda Aceh. Jumlah responden sebanyak 24 orang yang terdiri dari. Teknik pengambilan sampel pada penelitian ini seluruh populasi dijadikan sampel. Dalam penelitian data yang diambil secara langsung oleh penelitian terhadap sampel atau objek peneliti. 
Data primer meliputi nama, jenis kelamin, umur, pendidikan. Dan data sekunder merupakan data diperoleh dari panti asuhan nirmala berupa informasi tentang jumlah populasi.

Dalam penelitian ini proses pengolahan data dengan editing, coding, processing, dan cleaning. Cara penilaian penelitian dengan cara membagikan kuesioner kepada penjamah makanan sebelum dan sesudah. Penilaian-penilaian didasarkan pada suatu kriteria yang ditentukan sendiri atau menggunakan kriteria-kriteria yang telah ada. Analisa data yang digunakan yaitu analisa univariat dan analisa bivariat dimana analisa univariat menjelaskan kriteria masingmasing variabel independen dan dependen, yaitu tentang Pengaruh Penyuluhan Dengan Media Poster Terhadap Peningkatan Pengetahuan Dan Penerapan Teknik Pengolahan Bahan Makanan Pada Penjamah Makanan Dipanti Asuhan Nirmala. Dan Analisis bivariat dalam penelitian ini menggunakan uji Dependen $T$-test menggunakan perangkat komputer pada tingkat kepercayaan $95 \%(\alpha=0.05)$. Penyajian data dalam bentuk tektular dan tabular.

\section{Hasil}

Tabel 1. Pengetahuan dan penerapan teknik pengolahan bahan makanan sebelum dan sesudah penyuluhan dengan media poster

\begin{tabular}{lcccc}
\hline Kelompok & Min & Max & Mean & SD \\
\hline Pre test & & & & \\
Pengetahuan & 21 & 24 & 22.25 & 1.258 \\
Penerapan & 13 & 18 & 15.75 & 2.217 \\
\hline Post test & & & & \\
Pengetahuan & 30 & 33 & 31.75 & 1.258 \\
Penerapan & 22 & 27 & 24.25 & 2.217 \\
\hline
\end{tabular}

Berdasarkan hasil penelitian tabel 1 menunjukkan bahwa adanya perbedaan nilai ratarata pengetahuan dan penerapan sebelum penyuluhan yaitu 22.25 dan 15.75. Setelah dilakukan penyuluhan terjadi peningkatan nilai post test terhadap pengetahuan dan penerapan dengan nilai rata-rata 31.75 dan 24.25 .

Uji kenormalan data dalam studi ini penting dilakukan karena menggunakan data numerik serta uji statistic Dependen T-Tes. Berikut disajikan hasil uji kenormalan data pada table 2 .
Tabel 2. Hasil uji normalitas data

\begin{tabular}{|c|c|c|c|c|}
\hline Variabel & Rerata & SD & $95 \% \mathrm{Cl}$ & Nilai $p$ \\
\hline \multicolumn{5}{|c|}{ Pengetahuan } \\
\hline Sebelum & 22.25 & 1.258 & $\begin{array}{l}20.25- \\
24.25\end{array}$ & 0.406 \\
\hline Sesudah & 31.75 & 1.258 & $\begin{array}{l}29.75- \\
33.75\end{array}$ & 0.406 \\
\hline \multicolumn{5}{|c|}{ Penerapan } \\
\hline Sebelum & 15.75 & 2.217 & $\begin{array}{l}12.22- \\
19.28\end{array}$ & 0.798 \\
\hline Sesudah & 24.25 & 2.217 & $\begin{array}{l}20.72- \\
27.78\end{array}$ & 0.798 \\
\hline
\end{tabular}

Uji kenormalan data telah dilakukan dengan menggunakan uji shafirowilk (nilai $p>0.05$ ) yang berarti menujukkan data tersebut berdistribusi secara normal dan akan dilakukan pengujian selanjutnya.

Selanjutnya pada tabel 3, disajikan hasil penelitian terkait dengan pengaruh penyuluhan dengan media poster terhadap peningkatan pengetahuan dan penerapan pada penjamah makanan berdasarkan kelompok studi.

Tabel 3. Pengaruh penyuluhan dengan media poster terhadap peningkatan pengetahuan dan penerapan pada penjamah makanan

\begin{tabular}{|c|c|c|c|c|}
\hline Variabel & $\begin{array}{l}\text { Rerata } \\
\pm S D\end{array}$ & $\begin{array}{l}\text { Selisih } \\
\text { Rerata } \\
\pm \text { SD }\end{array}$ & $\begin{array}{l}95 \% \\
\mathrm{C} 1\end{array}$ & $\begin{array}{l}\text { Nilai } \\
p\end{array}$ \\
\hline Pengetahuan & $22.25 \pm$ & $9.50 \pm$ & 11.554 & 0.001 \\
\hline Sebelum & 1.258 & 1.291 & -7.446 & \\
\hline Pengetahuan & $31.75 \pm$ & & & \\
\hline Setelah & 1.258 & & & \\
\hline Penerapan & $15.75 \pm$ & $8.50 \pm$ & 12.288 & 0.006 \\
\hline Sebelum & 2.217 & 2.380 & -4.717 & \\
\hline Penerapan & $24.25 \pm$ & & & \\
\hline Setelah & 2.217 & & & \\
\hline
\end{tabular}

Berdasarkan tabel 3 dapat dilihat bahwa rerata pengetahuan pada penjamah makanan sebelum dilakukan penyuluhan adalah 22.25 terjadi peningkatan rerata setelah penyuluhan sebesar 9.50 yaitu 31.75. Begitu juga dengan hasil penerapan menggambarkan bahwa rerata sebelum dilakukan penyuluhan adalah 15.75 terjadi peningkatan rerata setelah penyuluhan sebesar 8.5 yaitu 24.25. Hasil uji statistik pada kategori pengetahuan didapatkan nilai $p=0.001(p<0.05)$ sehingga pada $\mathrm{Cl}: 95 \%$ Ho ditolak dan Ha diterima. 


\section{Pembahasan}

Penyuluhan kesehatan adalah kegiatan pendidikan kesehatan, yang dilakukan dengan menyebarkan pesan, menanamkan keyakinan sehingga masyarakat tidak hanya sadar, tahu dan mengerti, tetapi mau dan bisa melakukan anjuran yang ada hubungannya dengan kesehatan (Al Rahmad \& Almunadia, 2017). Peran media poster dalam proses pembelajaran sangat besar sekali bagi penyuluh dalam menyampaikan materi, dengan adanya media poster yang digunakan oleh penyuluh akan mempermudah dalam menyampaikan materi, dengan demikian peserta penyuluhan akan lebih mudah memahami materi yang disampaikan oleh penyuluh, sehingga tujuan pembelajaran dapat tercapai (Rahmaniati, 2015).

Pengetahuan dan penerapan dipengaruhi oleh beberapa faktor, seperti pendidikan, pekerjaan, umur, lingkungan dan budaya. Tingkat pendidikan merupakan salah satu faktor yang mempengaruhi pengetahuan dan keterampilan seseorang (Miranti \& Adi, 2016). Berdasarkan hasil tabulasi didapatkan bahwa sebagian besar responden yang berpendidikan SMA memiliki tingkat pengetahuan sedang dan tidak mudah menerima informasi serta tidak membuat ibu terdorong untuk mencari pengalaman baru yang ada diluar lingkungan. Dengan adanya pengalaman dan informasi yang didapatkan maka akan menjadi pengetahuan dan juga pendidikan diperlu untuk mendapatkan informasi misalnya makin tinggi tingkat pendidikan seseorang, makin tinggi pula pengetahuan yang dimiliki, sebaliknya pendidikan yang kurang akan menghambat perkembangan sikap seseorang terhadap nilainilai yang baru diperkenalkan (Purwaningsih \& Widiyaningsih, 2019).

Tercapainya tujuan penyuluhan tentu tak terlepas dari peran media. Karena merupakan salah satu sarana penting dalam proses pendidikan gizi. Dalam arti sempit, yang termasuk media adalah grafik, foto, gambar, alat mekanik dan elektronik yang dipergunakan untuk menangkap, memproses dan menyampaikan informasi visual dan verbal. Peran media sangat penting untuk menjelas pesan dan meningkatkan pengaruh proses penyuluhan gizi. Oleh sebab itu, seseorang penyuluh gizi, harus dapat mengenal, memilih, menggunakan dan nilai berbagai media yang paling sesuai dengan tujuan, sasaran dan situasi tempat pendidikan gizi dilakukan (Fitri et al., 2020).

Penelitian dengan memberikan penyuluhan menggunakan media poster terhadap peningkatan pengetahuan dan penerapan pada penjamah makanan tentang teknik pengolahan bahan makanan di panti asuhan nirmala yang di laksanakan selama 1 minggu terhadap 4 orang penjamah makanan, dengan memberikan penyuluhan selama 1 kali dan observasi sebelum dan sesudah 2 kali.

Hasil penelitian uji statistik dengan menggunakan uji T-Test Dependen terhadap tingkat pengetahuan melalui pemberian penyuluhan, pada kategori pengetahuan didapatkan nilai $p=0,001$ sehingga dapat disimpulkan bahwa pemberian penyuluhan pada penjamah makanan secara signifikan dapat meningkatkan pengetahuan mereka dan pada $\mathrm{Cl}: 95 \%$ Ho ditolak dan Ha diterima. Pada kategori penerapan juga terdapat nilai yang signifikan yaitu $p=0,006(p<0,05)$ sehingga pada $\mathrm{Cl}: 95 \% \mathrm{Ho}$ ditolak dan Ha diterima. Oleh karena itu, dapat disimpulkan bahwa adanya perbedaan antara pretest dan posttest pengetahuan dan penerapan pada penjamah makanan. Dengan kata lain, bahwa penyuluhan secara signifikan dapat meningkatkan pengetahuan dan penerapan pada penjamah makanan. Tercapainya sebuah penyuluhan dapat didukung dengan adanya media yang tepat. Dalam proses penyuluhan ini media yang digunakan adalah media poster dan $L C D$, menggunakan bahasa yang mudah mengerti sehingga peserta dengan mudah dapat memahami materi yang diberikan.

\section{Kesimpulan}

Penyuluhan menggunakan media poster secara signifikan dapat meningkatkan pengetahuan dan penerapan pada penjamah makanan dalam teknik pengolahan bahan makanan di panti asuhan Nirmala.

Saran, kepada tenaga penjamah makanan agar dapat menerapkan pengetahuan dan penerapan yang telah didapatkan dan disarankan bagi peneliti selanjutnya disarankan untuk melakukan penelitian lebih mendalam dengan menggunakan metode yang berbeda seperti metode Case Control yaitu dengan membandingkan kelompok kasus dan control 
dimana satu kelompok dilakukan penyuluhan dengan media poster sedangkan satu kelompok berikutnya tidak diberikan penyuluhan dengan media poster.

\section{Deklarasi Konflik Kepentingan}

Penulis telah menyatakan bahwa pada artikel ini tidak ada maupun terdapat potensi konflik kepentingan baik dari penulis maupun instansi sehubungan dengan penelitian yang telah dilakukan, baik berdasarkan kepengarangan, maupun publikasi.

\section{Ucapan Terima Kasih}

Ucapan terimakasih disampaikan kepada Ketua Jurusan Gizi Politeknik Kesehatan Kemenkes Aceh yang telah membantu kontribusi terhadap pelaksanaan penelitian. Selain itu, ucapan terima kasih juga kami sampaikan kepada Bapak pembimbing/ supervisor yang telah membantu perbaikan baik secara teknis maupun isi dalam pelaksanaan penelitian ini. Kepala Panti Asuhan Nirmala yang telah memberikan kesempatan dan membantu penulis dalam melakukan penelitian serta para responden.

\section{Daftar Rujukan}

Abdullah, F. (2016). Efektivitas Penyuluhan Higiene Dan Sanitasi Terhadap Peningkatan Pengetahuan, Sikap Dan Perilaku Penjamah Makanan Di Kantin Yang Dikelola Universitas Tanjungpura Pontianak. In Tanjungpura University (pp. 1-15). Tanjungpura University.

Al Rahmad, A. H., \& Almunadia, A. (2017). Pemanfaatan Media Flipchart dalam Meningkatkan Pengetahuan lbu Tentang Konsumsi Sayur dan Buah. Jurnal Kedokteran Syiah Kuala, 17(3), 140-146. https://doi.org/https://doi.org/10.24815/jks .v17i3.9062

Atmoko, T. P. H. (2017). Profesionalisme Chef Dalam Pengolahan Dan Meningkatkan Kualitas Makanan Di Cavinton Hotel Yogyakarta. Khasanah IImu-Jurnal Pariwisata
Dan Budaya, 8(2).

BPOM. (2016). Peraturan Kepala Badan Pengawas Obat Dan Makanan Republik Indonesia Nomor 13 Tahun 2016 Tentang Pengawasan Klaim Pada Label Dan Iklan Pangan Olahan. In Badan Pengawasan Obat dan Makanan. https://doi.org/10.1017/СBO978110741532 4.004

Creswell, J. W., \& Poth, C. N. (2017). Qualitative inquiry and research design: Choosing among five approaches. Sage publications.

Fitri, Y., Al Rahmad, A. H., Suryana, S., \& Nurbaiti, N. (2020). Pengaruh penyuluhan gizi tentang jajanan tradisional terhadap peningkatan pengetahuan dan perilaku jajan anak sekolah. AcTion: Aceh Nutrition Journal, 5(1), 13-18.

Miranti, E. A., \& Adi, A. C. (2016). Hubungan pengetahuan dengan sikap dan higiene perorangan (personal hygiene) penjamah makanan pada penyelenggaraan makanan asrama putri. Media Gizi Indonesia, 11(2), 120-126.

Purwaningsih, S., \& Widiyaningsih, E. N. (2019). Gambaran Lama Kerja Pengetahuan dan Perilaku Higiene Sanitasi Penjamah Makanan di Instalasi Gizi Rumah Sakit Umum Daerah dr. Soediran Mangun Sumarso Wonogiri. Profesi (Profesional Islam): Media Publikasi Penelitian, 16(2), 1-9.

Putri, B. R. A., Octaviany, V., \& Karsiwi, R. R. M. (2017). Analisis Teknik Pengolahan Makanan Halal Di 10 Binjai Restaurant Pnb Perdana Hotel And Suites On The Park, Kuala Lumpur 2017. EProceedings of Applied Science, 3(3), 20-29.

Rahmadhani, D., \& Sumarmi, S. (2017). Gambaran Penerapan Prinsip Higiene Sanitasi Makanan Di PT Aerofood Indonesia, Tangerang, Banten. Amerta Nutrition, 1(4), 291-299.

Rahmaniati, R. (2015). Penggunaan media poster untuk meningkatkan hasil belajar IPA peserta didik kelas VB SDN 6 Langkai Palangka Raya. Pedagogik Jurnal Pendidikan, 10(2), 59-64.

Syahrizal, S. (2017). Hygiene Sanitasi Penjamah Makanan Terhadap Kandungan Escherichia Coli Diperalatan Makan Pada Warung Makan. AcTion: Aceh Nutrition Journal, 2(2), 132136.

Wardhani, A. K. (2014). Analisis teknik pengolahan 
makanan dan pola makan santri di pesantren

http://digilib.unimed.ac.id/id/eprint/19198 ar-raudhatul hasanah [Universitas Negeri Medan]. In Universitas Negeri Medan. 